\title{
Self-reported Smell and Taste Disorders in Patients With COVID-19: A Japanese Single-center Study
}

\author{
KEISUKE YAMAMOTO ${ }^{1,2}$, YOSHIHIRO FUJIYA ${ }^{3}$, KOJI KURONUMA ${ }^{4}$, NORIKO OGASAWARA ${ }^{1,2}$, \\ TSUYOSHI OHKUNI ${ }^{1}$, SHIN-ICHI YOKOTA ${ }^{2}$, SATOSHI TAKAHASHI ${ }^{3}$ and KENICHI TAKANO ${ }^{1}$ \\ ${ }^{1}$ Department of Otorhinolaryngology Head \& Neck Surgery, \\ Sapporo Medical University School of Medicine, Sapporo, Japan; \\ ${ }^{2}$ Department of Microbiology, Sapporo Medical University School of Medicine, Sapporo, Japan; \\ ${ }^{3}$ Department of Infection Control \& Laboratory Medicine, \\ Sapporo Medical University School of Medicine, Sapporo, Japan; \\ ${ }^{4}$ Department of Respiratory Medicine and Allergology, \\ Sapporo Medical University School of Medicine, Sapporo, Japan
}

\begin{abstract}
Background/Aim: Smell and taste disorders are among the most common symptoms of COVID-19. However, the relationship between smell and taste disorders and systemic symptoms is not fully understood in Japan. Patients and Methods: Questionnaires were mailed to 105 of 111 COVID-19 patients who were hospitalized at our hospital between March and July 2020 in Japan. Results: A total of 74 patients (response rate: $70.5 \%$ ) completed the survey. Of these, six patients $(8.1 \%)$ presented with smell disorders only, $16(21.6 \%)$ presented with taste disorders only, and 17 (23.0\%) presented with both smell and taste disorders. The mean Visual Analog Scale for smell and taste was 0.5 and 20 , respectively, at the time of the most severe symptoms. Conclusion: Among COVID-19 patients in Japan, smell and taste disorders are often followed by fever and may not be the first symptoms. Sense of smell is particularly impaired. These symptoms often improve, although they sometimes persist for a long time as sequelae.
\end{abstract}

The COVID-19 epidemic is still ongoing around the world. In Japan, the first case was reported in 2020, and a state of emergency was declared. Despite the vaccination incentives,

This article is freely accessible online.

Correspondence to: Keisuke Yamamoto, Department of Otorhinolaryngology Sapporo Medical University School of Medicine, Minami 1-jo Nishi 16-chome, Chuo-ku, Sapporo, Hokkaido, 060-0061, Japan. Tel: +81 116112111, Ext. 34910, Fax: +81 116155405, e-mail: yamakei0622@sapmed.ac.jp

Key Words: Smell disorder, taste disorder, self-report, Visual Analog Scale, COVID-19, SARS-CoV2. containment of the infection has not yet been achieved. According to Asian reports, the most common COVID-19 symptoms are fever, cough, dyspnea, sputum production, myalgia, arthralgia, headache, diarrhea, rhinorrhea, and sore throat $(1,2)$. Smell disorder is also one of the most common symptoms of COVID-19 (3), and, of all the associated symptoms, is the best predictor of COVID-19 status (4). However, the order in which smell and taste disorders tend to appear relative to other symptoms, and the relationship between smell and taste disorders and systemic symptoms, is not fully understood. It is also unclear how other symptoms develop after the onset of smell and taste disorders. Furthermore, there are insufficient reports on the incidence, clinical course, and severity of smell and taste disorders in Japan. There have been many questionnairebased studies on smell and taste disorders in COVID-19, and many findings have been revealed (4-8).

In this study, we examined the patient background, severity, clinical course, and sequelae of COVID-19 smell and taste disorders in Japan, and the relationship between smell and taste disorders and systemic symptoms. To our knowledge, this is the first report to describe smell and taste disorders in COVID-19 patients in Japan.

\section{Patients and Methods}

The study included patients who were admitted to our hospital between March and July 2020 with a positive polymerase chain reaction (PCR) test result for SARS-CoV-2 in nasopharyngeal swabs. Questionnaires were sent by mail to 105 of the 111 hospitalized patients, excluding those who had died, and those who responded were included in the study. Smell disorder was assessed using the visual analog scale (VAS) and self-administered odor questionnaire (SAOQ) (9), and taste disorder was assessed using the VAS. The content of the clinical course questionnaire is shown in 


\section{Questionnaire}

1. Did you have a smell or taste disorder?

2. What was the severity of the smell/taste disorder when they were most severe? - VAS, SAOQ

3. When were the smell/taste disorders first noticed?

4. Did you have any other symptoms BEFORE the onset of smell/taste disorders?

5. What symptoms did you have BEFORE the onset of smell/taste disorders?

6. Did your condition worsen or improve after the smell/taste disorders were observed?

7. What symptoms did you have AT THE TIME of the smell/taste disorders?

8. Did the smell/taste disorders resolve afterwards?

9. Did the smell/taste disorders resolve?

Figure 1. Contents of questionnaires about the clinical course. Participants were queried using a posted questionnaire about the presence or absence of smell and/or taste disorders, the severity of the disorders, the clinical course of the smell and taste disorders and systemic symptoms, and the presence or absence of current smell and/or taste disorders. Additionally, the patients were asked whether the onset of smell and/or taste disorders occurred before or after the PCR test. Smell disorder was assessed using the visual analog scale (VAS) and the self-administered odor questionnaire (SAOQ), and taste disorder was assessed using the VAS.

Figure 1. Clinical data were obtained from a review of the electronic medical records (EMR). Fisher's exact test was used to compare the proportions of symptomatic patients between the two independent groups. Statistical analysis (age, $<60$ years old $v s . \geq 60$ years old; Sex, male $v s$. female; Severity, mild to moderate $v s$. severe) was done using $\mathrm{R}$ (NIH, USA), with a $p$-value of 0.05 indicating a significant difference. This study was approved by the ethics board of Sapporo Medical University (\#322-54).

\section{Results}

A total of 74 people responded (response rate: $70.5 \%$ ). The mean period from receiving a positive PCR test result to completing the questionnaire was 105.3 days (standard deviation: 36.8 days; median: 107.5 days). Patient demographics are shown in Table I. Patients in their 20s had the highest percentage of smell and taste disorders (85.7\%). Twenty-three patients $(31.1 \%)$ had smell disorders and thirty-two patients $(44.6 \%)$ had taste disorders. The degree of smell and taste disorders is shown in Figure 2. The mean VAS for the overall sense of smell was $19 \mathrm{~mm}$ (standard deviation: $27.9 \mathrm{~mm}$ ), the mean VAS for perfume was $13 \mathrm{~mm}$ (standard deviation: $25.1 \mathrm{~mm}$ ), the mean VAS for feces was $10 \mathrm{~mm}$ (standard deviation: $22 \mathrm{~mm}$ ), and the mean VAS for food was $12 \mathrm{~mm}$ (standard deviation: $21.2 \mathrm{~mm}$ ). The mean SAOQ was $14.1 \%$ (standard deviation: $24.3 \%$ ). The mean VAS for the taste of food was $31.6 \mathrm{~mm}$ (standard deviation: $31.5 \mathrm{~mm}$ ). Sense of smell was particularly impaired.
Table I. Demographics of symptomatic patients.

\begin{tabular}{lc}
\hline Demographics & Symptomatic patients \\
\hline Patients, n (\%) & $39(52.7)$ \\
Symptoms, n (\%) & \\
Loss of smell, only & $6(8.1)$ \\
Loss of taste, only & $16(21.6)$ \\
Both & $17(23.0)$ \\
Age, y (\%) & \\
Mean age \pm SD & $50.3 \pm 16.5$ \\
Median (range) & $52.0(11$ to 80$)$ \\
Each ages, n (\%) & \\
$10 \mathrm{~s}$ & $1(33.3)$ \\
$20 \mathrm{~s}$ & $6(85.7)$ \\
$30 \mathrm{~s}$ & $3(60.0)$ \\
$40 \mathrm{~s}$ & $6(75.0)$ \\
$50 \mathrm{~s}$ & $11(68.8)$ \\
$60 \mathrm{~s}$ & $8(44.4)$ \\
$70 \mathrm{~s}$ & $3(30.0)$ \\
$80 \mathrm{~s}$ & $1(16.7)$ \\
Gender, n (\%) & $110(41$ to 172$)$ \\
Male & \\
Female & $24(52.2)$ \\
Days after PCR positive test, days & \\
Mean days \pm SD & \\
Median (range) & \\
\hline
\end{tabular}

The clinical course of smell and taste disorders is shown in Table II. The onset of these disorders was before PCR testing in 23 cases $(59 \%)$ and after PCR testing in 16 cases (41\%). Thirty-two cases $(82.1 \%)$ had other symptoms before the onset of smell and/or taste disorders. The course of COVID-19 after the onset of smell and taste disorders was improvement in 15 cases $(38.5 \%)$, no change in 15 cases $(38.5 \%)$, and worsening in eight cases $(20.5 \%)$. Subsequent smell and taste disorders improved in 32 patients $(82.1 \%)$. At a mean of 113.1 days, smell and taste disorders were still present in ten patients $(25.6 \%)$.

Details of other symptoms before and after the onset of smell and taste disorders are shown in Figure 3. Before the onset of smell and taste disorders, systemic symptoms such as fever, malaise, fatigue, chills, headache, and respiratory symptoms such as cough were more prominent, while upper respiratory symptoms were less frequent. However, these systemic symptoms and respiratory symptoms had decreased by the time patients became aware of their smell and taste disorders. The total number of multiple-response symptoms was 139 before the onset of symptoms compared with 82 at the time of the onset of symptoms, which was lower when the subjects became aware of smell and/or taste disorders (Figure 3B).

The prevalence and clinical course of the disease by age ( $<60$ years $v s .>60$ years), sex (male $v s$. female), and severity (severe cases $v s$. mild-to-moderate cases) are shown in Table 


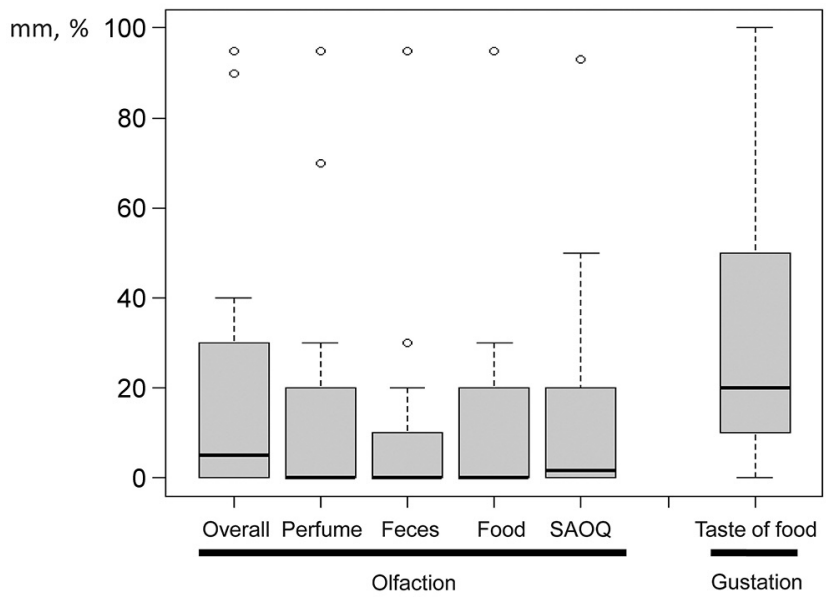

Figure 2. Visual analog scale of olfaction and taste self-administered odor questionnaire. Visual analog scale (VAS) of olfaction consists of overall, perfume, feces, and food. The median VAS for the overall sense of smell was $5 \mathrm{~mm}$ (standard deviation: $27.9 \mathrm{~mm}$ ), the median VAS for perfume was $0 \mathrm{~mm}$ (standard deviation: $25.1 \mathrm{~mm}$ ), the median VAS for feces was $0 \mathrm{~mm}$ (standard deviation: $22 \mathrm{~mm}$ ), and the median VAS for food was $0 \mathrm{~mm}$ (standard deviation: $21.2 \mathrm{~mm}$ ). The median selfadministered odor questionnaire (SAOQ) was $1.7 \%$ (standard deviation: $24.3 \%$ ). The median VAS for taste of food was $20 \mathrm{~mm}$ (standard deviation: $31.5 \mathrm{~mm}$ ).

III. The prevalence of smell disorders was significantly higher in the $<60$ years group $(61.8 \%)$ than in the $>60$ years group $(8 \% ; p<0.001)$. The prevalence of taste disorders was significantly higher $(p<0.05)$ in the $<60$ years group $(64.7 \%)$ than in the $>60$ years group (32.4\%). The prevalence did not differ according to sex or severity of disease. The clinical course did not differ according to age, sex, or severity of disease.

\section{Discussion}

We conducted a questionnaire survey on smell and taste disorders in patients with COVID-19 treated at our hospital. These symptoms were observed in $31.1 \%$ and $44.6 \%$ of patients, respectively. The subjective sense of smell was particularly impaired. Smell and taste disorders are symptoms that occur early in the development of COVID-19, but many cases had fever and general malaise before smell and taste disorders. Smell and taste disorders improved in more than $80 \%$ of cases. However, at a mean of 113 days after a diagnosis of COVID-19, 25.6\% of patients remained symptomatic. Smell and taste disorders were significantly more frequent in patients younger than 60 years. To our knowledge, this is the first report to describe smell and taste disorders in COVID-19 patients in Japan. Our results provide new insights into the clinical course of smell and taste disorders and the relationship between these disorders in these patients.
Table II. Clinical course.

\begin{tabular}{lrr}
\hline & No. & $\%$ \\
\hline Loss of smell/taste onset & & \\
$\quad$ Before PCR test & 23 & 59 \\
After PCR test & 16 & 41 \\
Other symptoms before the loss of smell/taste & & \\
$\quad$ Presence & 32 & 82.1 \\
$\quad$ Absence & 7 & 17.9 \\
The course of COVID-19 after the loss & & \\
of smell/taste was observed & & \\
Improve & 15 & 38.5 \\
Worsen & 8 & 20.5 \\
No change & 15 & 38.5 \\
Unknown & 1 & 2.6 \\
Improvement of smell/taste following & & \\
the onset of the disease & & \\
Yes & 32 & 82.1 \\
No & 1 & 2.6 \\
No change & 5 & 12.8 \\
Unknown & 1 & 2.6 \\
Current loss of smell/taste & & \\
Yes & 10 & 25.6 \\
No & 28 & 71.8 \\
Unknown & 1 & 2.6 \\
\end{tabular}

The worldwide incidence of smell and taste disorders due to COVID-19 is reported to be $47.85 \%$ (10) and $47.5 \%$ (11), respectively. The prevalence of smell disorder has been reported to be $54.4 \%$ in Europe, $51.11 \%$ in North America, and $31.3 \%$ in Asia, while the prevalence of taste disorders has been reported to be $53.1 \%$ in Europe, $46.2 \%$ in North America, and $19.4-57.5 \%$ in Asia $(10,11)$. In the present study, $31 \%$ had smell disorders and $44 \%$ had taste disorders, which is consistent with previous reports. The reasons for the differences in smell and taste disorders by country are due to differences in the frequency of variants of angiotensin-converting enzyme 2 (ACE2) among ethnic groups, phylogenetic mutation, and heterogeneity in study designs (11). The frequency of smell and taste disorders is expected to continue to change due to the current spread of mutant viruses. The relationship between viral mutations and the prevalence of smell and taste disorders should continue to be closely monitored.

Smell disorder in COVID-19 patients has been found to be different from post-infectious olfactory dysfunction. Patients with post-infectious olfactory dysfunction are often aware of their smell disorder while their upper respiratory symptoms persist, and complain of more severe rhinitis symptoms than usual during that time (12). Conversely, nasal discharge and nasal obstruction symptoms are reported to be less common in COVID-19 patients $(5,13-18)$. In this study, rhinorrhea and nasal congestion were observed in six and seven cases, respectively, before the onset of symptoms and in three and four cases, respectively, at the onset of symptoms. 
A

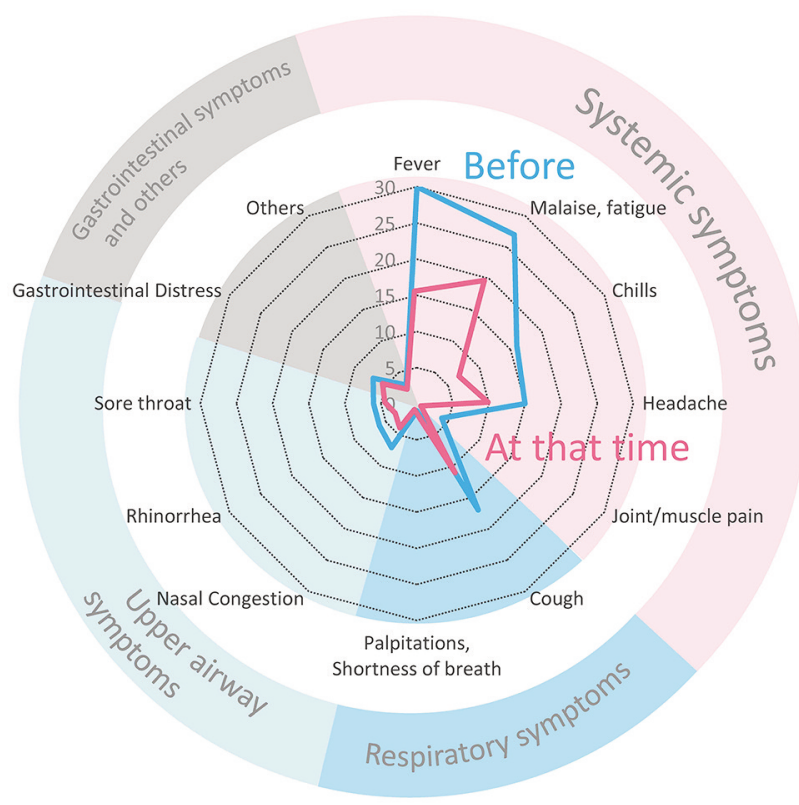

B

\begin{tabular}{lrr} 
& Other symptoms, N \\
& Before & At the time \\
\hline Fever & 30 & 15 \\
Malaise, fatigue & 27 & 19 \\
Chills & 16 & 7 \\
Headache & 15 & 10 \\
Joint/muscle pain & 4 & 1 \\
Cough & 17 & 11 \\
Palpitations, Shortness & 1 & 1 \\
of breath & 7 & 4 \\
Nasal Congestion & 6 & 3 \\
Rhinorrhea & 6 & 4 \\
Sore throat & 7 & 5 \\
Gastrointestinal Distress & 3 & 2 \\
Others & 139 & 82
\end{tabular}

Figure 3. The details of other symptoms before and after the onset of smell and taste disturbances. Symptoms of olfactory and gustatory disturbances before (blue) and after (pink) the onset of symptoms are shown by a circle graph showing systemic symptoms, respiratory symptoms, upper respiratory symptoms, and gastrointestinal symptoms $(A)$, and total number of symptoms $(B)$.

With respect to the onset of smell and taste disorders from the standpoint of COVID-19, it is reported that within 5 days of onset (19), $60 \%$ and $90 \%$ of smell and taste disorders precede hospitalization, respectively (20), and $33 \%$ to $60 \%$ of smell disorders appear before or at the same time as other symptoms (20-22). In the present report, 59\% of patients with smell and taste disorders were aware of their symptoms before PCR testing, which indicates that symptoms occur relatively early. However, since $82.1 \%$ of patients had other symptoms before becoming aware of smell and taste disorders, it is difficult to conclude that smell and taste disorders are the first symptoms of COVID-19. In the present study, fever was the most common symptom that preceded smell and taste disorders, followed by systemic and respiratory symptoms, such as malaise, cough, chills, and headache. When looking at COVID-19 from the standpoint of smell and taste disorders, $20.5 \%$ of cases showed worsening of COVID-19 after the appearance of smell and taste disorders, while $38.5 \%$ showed no change and $38.5 \%$ showed improvement. Furthermore, the total number of symptoms "at that time" decreased compared with the total number of symptoms "before" the appearance of smell and taste disorders. Therefore, it is expected that patients with
COVID-19 often show a gradual improvement after the onset of smell and taste disorders.

It has been reported that smell and taste disorders in patients with COVID-19 improve early in the course of the disease $(21,23)$; the mean time from smell disorder onset to recovery onset was 11.6 days. One study reported that recovery started between the 4th and the 15th day after smell disorder onset in $78.4 \%$ of patients (24). Psychophysical taste tests have confirmed the presence of true taste disorder in nearly half of patients tested, but with mean scores returning to normal within 3 weeks from onset (25). This is clearly different from the course of post-infectious olfactory dysfunction, which takes more time to improve. Reden et al. reported that the post-infectious olfactory dysfunction of $32 \%$ of patients improved after a mean observation period of 13 months (26), whereas Kondo et al. reported a gradual improvement after more than one year (12). The duration of smell and taste disorders was not investigated in detail in the present report, but $82.1 \%$ of patients who were aware of their symptoms reported that the symptoms improved after onset of the disease. However, not all cases of COVID-19-induced olfactory disorders improve so quickly, with residual disorder reported in $15 \%$ of patients at 60 days and $4.7 \%$ at 
Table III. The prevalence and clinical course of disease by age, sex, and severity.

\begin{tabular}{|c|c|c|c|c|c|c|c|c|c|c|}
\hline & & \multicolumn{2}{|c|}{ Age } & \multirow[b]{2}{*}{$p$-Value } & \multicolumn{2}{|c|}{ Gender } & \multirow[b]{2}{*}{$p$-Value } & \multicolumn{2}{|c|}{ Severity } & \multirow[b]{2}{*}{$p$-Value } \\
\hline & & $<60$ y.o. & $\geq 60$ y.o. & & Male & Female & & $\begin{array}{l}\text { Mild to } \\
\text { moderate }\end{array}$ & Severe & \\
\hline \multirow[t]{2}{*}{ Loss of smell } & Yes & 21 & 2 & & 9 & 14 & \multirow[t]{2}{*}{0.787} & 22 & 1 & \multirow[t]{2}{*}{0.66} \\
\hline & No & 12 & 23 & $<0.001$ & 16 & 19 & & 47 & 5 & \\
\hline \multirow[t]{2}{*}{ Loss of taste } & Yes & 22 & 11 & $<0.05$ & 14 & 19 & \multirow[t]{2}{*}{0.812} & 30 & 3 & \multirow[t]{2}{*}{1} \\
\hline & No & 12 & 23 & & 16 & 19 & & 39 & 3 & \\
\hline \multirow[t]{2}{*}{ Symptom onset } & Before PCR & 17 & 6 & 0.498 & 9 & 14 & \multirow[t]{2}{*}{0.531} & 22 & 1 & \multirow[t]{2}{*}{0.557} \\
\hline & After PCR & 10 & 6 & & 8 & 8 & & 14 & 2 & \\
\hline \multirow{2}{*}{$\begin{array}{l}\text { Other symptoms } \\
\text { before the loss } \\
\text { of smell/taste }\end{array}$} & Presence & 23 & 9 & 0.654 & 13 & 19 & \multirow[t]{2}{*}{0.677} & 30 & 2 & \multirow[t]{2}{*}{0.45} \\
\hline & Absence & 4 & 3 & & 4 & 3 & & 6 & 1 & \\
\hline \multirow{4}{*}{$\begin{array}{l}\text { The clinical course } \\
\text { of COVID-19 } \\
\text { after the loss } \\
\text { of smell/taste }\end{array}$} & Improve & 8 & 7 & 0.095 & 6 & 9 & \multirow[t]{4}{*}{0.955} & 14 & 1 & \multirow[t]{4}{*}{1} \\
\hline & Worsen & 8 & 0 & & 4 & 4 & & 7 & 1 & \\
\hline & No change & 10 & 5 & & 7 & 8 & & 14 & 1 & \\
\hline & Unknown & 1 & 0 & & 0 & 1 & & 1 & 0 & \\
\hline Subsequent & Yes & 23 & 9 & 0.505 & 14 & 9 & \multirow[t]{4}{*}{0.439} & 31 & 1 & \multirow[t]{4}{*}{0.077} \\
\hline improvement & No & 1 & 0 & & 0 & 1 & & 1 & 0 & \\
\hline \multirow[t]{2}{*}{ in smell/taste } & No change & 2 & 3 & & 2 & 2 & & 3 & 2 & \\
\hline & Unknown & 1 & 0 & & 0 & 1 & & 1 & 0 & \\
\hline \multirow{3}{*}{$\begin{array}{l}\text { Current loss } \\
\text { of smell/taste }\end{array}$} & Yes & 7 & 3 & 1 & 3 & 7 & \multirow[t]{3}{*}{0.464} & 8 & 2 & \multirow[t]{3}{*}{0.228} \\
\hline & No & 19 & 9 & & 14 & 14 & & 27 & 1 & \\
\hline & Unknown & 1 & 0 & & 0 & 1 & & 1 & 0 & \\
\hline
\end{tabular}

Statistically significant $p$-Values are shown in bold.

6 months after infection (27). In the present study, $25.6 \%$ of patients had residual smell and taste disorders at a mean of 113 days after PCR positivity. Currently, there are four known mechanisms of COVID-19-induced smell disorder, which are as follows: 1) Obstruction of the olfactory cleft; 2) Infection of the sustentacular supporting cells, which express ACE2; 3) Injury to the olfactory bulb; and 4) Injury to olfactory sensory cells via neuropilin-1 receptor (NRP1) $(28,29)$. The recovery time from olfactory damage by these mechanisms is thought to be as follows. 1) Swelling of the olfactory cleft is said to recover within 7-10 days $(29,30)$. 2) Sustentacular cells have been reported to be damaged by the virus via the ACE2 receptor, followed by generation of new supporting cells by stem cells, whereby it takes about 10 days to regain the sense of smell (31). 3) A preliminary study recently reported that SARS-CoV-2 specifically affects glial cells of the olfactory bulb, which have a higher ACE2 expression than neurons (32). A larger affected area of the sensory epithelium could induce a more profound destruction of the epithelium and the death of more olfactory receptor neurons (31). 4) Direct damage to the olfactory nerve and subsequent olfactory bulb due to NRP1-mediated infection has been reported (29). Since NRP1 is expressed in almost all olfactory epithelia, including the olfactory nerve and progenitor cells, it is thought that binding to NRP1 in progenitor cells may result in long-term olfactory dysfunction (29). Therefore, considering the possible mechanisms that lead to olfactory damage, swelling of the olfactory cleft and damage to supporting cells may result in a relatively short recovery of olfaction, whereas extensive damage to the olfactory epithelium or damage to the olfactory nerve or progenitor cells via NRP1 may result in long-term olfactory damage.

Among patients with mild-to-moderate COVID-19 symptoms in Taiwan, smell disorder was more frequently observed in young patients (33). In this study, smell and taste disorders were significantly more common in patients under 60 years of age. However, the underlying mechanism is not clear (34). Aging is a factor in olfactory degeneration. With increasing age, the integrity of the olfactory epithelium and the size of the olfactory bulb decrease (35). Therefore, the elderly may simply be unaware that they have an impaired sense of smell.

The present study was based on questionnaires for past events, which means that recall bias is a possibility. Since subjective olfactory tests are not always reliable (36), it would be desirable to use other sensory tests for olfaction and gustation for a more detailed study. In addition, because the course of smell and taste disorders are combined, an accurate assessment of the course of smell and taste disorders could not be achieved. Furthermore, the small number of patients in this study could explain the lack of 
significant differences between patients with severe and mild-to-moderate disease severities.

We conducted the first questionnaire survey on olfactory and gustatory disorders in patients with COVID-19 in Japan. The results support previous findings in this field, but reveal more about the progression of smell and taste disorders in COVID-19 in patients in Japan. In the course of COVID-19 (37), smell and taste disorders are often followed by fever and may not be the first symptoms. Sense of smell is particularly impaired. The smell and taste disorders caused by COVID-19 infection often improve, although they sometimes persist for a long time as sequelae. This is thought to be related to the mechanism of infection of the olfactory epithelium and requires further investigation.

\section{Conflicts of Interest}

All Authors declare they have no conflicts of interest regarding this article. The Authors received no financial support for the research or publication of this article.

\section{Authors' Contributions}

$\mathrm{KY}$ and $\mathrm{KT}$ made substantial contributions to conception and design. YF and KK made substantial contributions to acquisition of data. KY, NO, TO and KT analyzed and interpreted the data. KY, YF, KK, NO, TO, SY, ST and TK drafted the article or revised it critically for important intellectual content. KY, SY, ST, KT gave final approval of the version to be published.

\section{References}

1 Young BE, Ong SWX, Kalimuddin S, Low JG, Tan SY, Loh J, Ng OT, Marimuthu K, Ang LW, Mak TM, Lau SK, Anderson DE, Chan KS, Tan TY, Ng TY, Cui L, Said Z, Kurupatham L, Chen MI, Chan M, Vasoo S, Wang LF, Tan BH, Lin RTP, Lee VJM, Leo YS, Lye DC and Singapore 2019 Novel Coronavirus Outbreak Research Team: Epidemiologic features and clinical course of patients infected with SARS-CoV-2 in Singapore. JAMA 323(15): 1488-1494, 2020. PMID: 32125362. DOI: 10.1001/jama.2020.3204

2 Wan S, Xiang Y, Fang W, Zheng Y, Li B, Hu Y, Lang C, Huang D, Sun Q, Xiong Y, Huang X, Lv J, Luo Y, Shen L, Yang H, Huang $G$ and Yang R: Clinical features and treatment of COVID-19 patients in northeast Chongqing. J Med Virol 92(7): 797-806, 2020. PMID: 32198776. DOI: 10.1002/jmv.25783

3 Lechien JR, Chiesa-Estomba CM, Place S, Van Laethem Y, Cabaraux P, Mat Q, Huet K, Plzak J, Horoi M, Hans S, Rosaria Barillari M, Cammaroto G, Fakhry N, Martiny D, Ayad T, Jouffe L, Hopkins C, Saussez S and COVID-19 Task Force of YOIFOS: Clinical and epidemiological characteristics of 1420 European patients with mild-to-moderate coronavirus disease 2019. J Intern Med 288(3): 335-344, 2020. PMID: 32352202. DOI: 10.1111/joim.13089

4 Menni C, Valdes AM, Freidin MB, Sudre CH, Nguyen LH, Drew DA, Ganesh S, Varsavsky T, Cardoso MJ, El-Sayed Moustafa JS, Visconti A, Hysi P, Bowyer RCE, Mangino M,
Falchi M, Wolf J, Ourselin S, Chan AT, Steves CJ and Spector TD: Real-time tracking of self-reported symptoms to predict potential COVID-19. Nat Med 26(7): 1037-1040, 2020. PMID: 32393804. DOI: 10.1038/s41591-020-0916-2

5 Printza A and Constantinidis J: The role of self-reported smell and taste disorders in suspected COVID-19. Eur Arch Otorhinolaryngol 277(9): 2625-2630, 2020. PMID: 32447496. DOI: $10.1007 / \mathrm{s} 00405-020-06069-6$

6 Lechien JR, Cabaraux P, Chiesa-Estomba CM, Khalife M, Hans S, Calvo-Henriquez C, Martiny D, Journe F, Sowerby L and Saussez S: Objective olfactory evaluation of self-reported loss of smell in a case series of 86 COVID-19 patients. Head Neck 42(7): 1583-1590, 2020. PMID: 32437033. DOI: 10.1002/hed.26279

7 Yan CH, Faraji F, Prajapati DP, Ostrander BT and DeConde AS: Self-reported olfactory loss associates with outpatient clinical course in COVID-19. Int Forum Allergy Rhinol 10(7): 821-831, 2020. PMID: 32329222. DOI: 10.1002/alr.22592

8 Hopkins C, Surda P, Whitehead E and Kumar BN: Early recovery following new onset anosmia during the COVID-19 pandemic - an observational cohort study. J Otolaryngol Head Neck Surg 49(1): 26, 2020. PMID: 32366299. DOI: 10.1186/s40463-020-00423-8

9 Takebayashi H, Tsuzuki K, Oka H, Fukazawa K, Daimon T and Sakagami M: Clinical availability of a self-administered odor questionnaire for patients with olfactory disorders. Auris Nasus Larynx 38(1): 65-72, 2011. PMID: 20594785. DOI: 10.1016/ j.anl.2010.05.013

10 Saniasiaya J, Islam MA and Abdullah B: Prevalence of olfactory dysfunction in Coronavirus disease 2019 (COVID-19): a metaanalysis of 27,492 patients. Laryngoscope 131(4): 865-878, 2021. PMID: 33219539. DOI: 10.1002/lary.29286

11 Kim JW, Han SC, Jo HD, Cho SW and Kim JY: Regional and chronological variation of chemosensory dysfunction in COVID19: a meta-analysis. J Korean Med Sci 36(4): e40, 2021. PMID: 33496090. DOI: $10.3346 / \mathrm{jkms} .2021 .36 . \mathrm{e} 40$

12 Kondo K: Postviral olfactory disorder. Journal of Japan Association on Odor Environment 45(4): 271-277, 2019. DOI: $10.2171 /$ jao. 45.271

13 Kaye R, Chang CWD, Kazahaya K, Brereton J and Denneny JC 3rd: COVID-19 anosmia reporting tool: initial findings. Otolaryngol Head Neck Surg 163(1): 132-134, 2020. PMID: 32340555. DOI: $10.1177 / 0194599820922992$

14 Lechien JR, Chiesa-Estomba CM, Hans S, Barillari MR, Jouffe L and Saussez S: Loss of smell and taste in 2013 European patients with mild to moderate COVID-19. Ann Intern Med 173(8): 672-675, 2020. PMID: 32449883. DOI: 10.7326/M202428

15 Tong JY, Wong A, Zhu D, Fastenberg JH and Tham T: The prevalence of olfactory and gustatory dysfunction in COVID-19 patients: a systematic review and meta-analysis. Otolaryngol Head Neck Surg 163(1): 3-11, 2020. PMID: 32369429. DOI: 10.1177/0194599820926473

16 Vaira LA, Salzano G, Deiana G and De Riu G: Anosmia and ageusia: Common findings in COVID-19 patients. Laryngoscope 130(7): 1787, 2020. PMID: 32237238. DOI: 10.1002/lary.28692

17 von Bartheld CS, Hagen MM and Butowt R: Prevalence of chemosensory dysfunction in COVID-19 patients: a systematic review and meta-analysis reveals significant ethnic differences. ACS Chem Neurosci 11(19): 2944-2961, 2020. PMID: 32870641. DOI: 10.1021/acschemneuro.0c00460 
18 Xydakis MS, Dehgani-Mobaraki P, Holbrook EH, Geisthoff UW, Bauer C, Hautefort C, Herman P, Manley GT, Lyon DM and Hopkins C: Smell and taste dysfunction in patients with COVID19. Lancet Infect Dis 20(9): 1015-1016, 2020. PMID: 32304629 DOI: 10.1016/S1473-3099(20)30293-0

19 Vaira LA, Deiana G, Fois AG, Pirina P, Madeddu G, De Vito A, Babudieri S, Petrocelli M, Serra A, Bussu F, Ligas E, Salzano G and De Riu G: Objective evaluation of anosmia and ageusia in COVID-19 patients: Single-center experience on 72 cases. Head Neck 42(6): 1252-1258, 2020. PMID: 32342566. DOI: 10.1002/ hed.26204

20 Giacomelli A, Pezzati L, Conti F, Bernacchia D, Siano M, Oreni L, Rusconi S, Gervasoni C, Ridolfo AL, Rizzardini G, Antinori $\mathrm{S}$ and Galli M: Self-reported olfactory and taste disorders in patients with severe acute respiratory Coronavirus 2 infection: a cross-sectional study. Clin Infect Dis 71(15): 889-890, 2020 PMID: 32215618. DOI: $10.1093 / \mathrm{cid} / \mathrm{ciaa330}$

21 Lechien JR, Chiesa-Estomba CM, De Siati DR, Horoi M, Le Bon SD, Rodriguez A, Dequanter D, Blecic S, El Afia F, Distinguin L, Chekkoury-Idrissi Y, Hans S, Delgado IL, CalvoHenriquez C, Lavigne P, Falanga C, Barillari MR, Cammaroto G, Khalife M, Leich P, Souchay C, Rossi C, Journe F, Hsieh J, Edjlali M, Carlier R, Ris L, Lovato A, De Filippis C, Coppee F, Fakhry N, Ayad T and Saussez S: Olfactory and gustatory dysfunctions as a clinical presentation of mild-to-moderate forms of the coronavirus disease (COVID-19): a multicenter European study. Eur Arch Otorhinolaryngol 277(8): 2251-2261, 2020 PMID: 32253535. DOI: 10.1007/s00405-020-05965-1

22 Yan CH, Faraji F, Prajapati DP, Boone CE and DeConde AS: Association of chemosensory dysfunction and COVID-19 in patients presenting with influenza-like symptoms. Int Forum Allergy Rhinol 10(7): 806-813, 2020. PMID: 32279441. DOI: 10.1002/alr.22579

23 Chary E, Carsuzaa F, Trijolet JP, Capitaine AL, Roncato-Saberan M, Fouet K, Cazenave-Roblot F, Catroux M, Allix-Beguec C and Dufour X: Prevalence and recovery from olfactory and gustatory dysfunctions in Covid-19 infection: a prospective multicenter study. Am J Rhinol Allergy 34(5): 686-693, 2020. PMID: 32527141. DOI: 10.1177/1945892420930954

24 Gorzkowski V, Bevilacqua S, Charmillon A, Jankowski R, Gallet P, Rumeau C and Nguyen DT: Evolution of olfactory disorders in COVID-19 patients. Laryngoscope 130(11): 2667-2673, 2020. PMID: 32617990. DOI: 10.1002/lary.28957

25 Vaira LA, Hopkins C, Salzano G, Petrocelli M, Melis A, Cucurullo M, Ferrari M, Gagliardini L, Pipolo C, Deiana G, Fiore V, De Vito A, Turra N, Canu S, Maglio A, Serra A, Bussu F, Madeddu G, Babudieri S, Giuseppe Fois A, Pirina P, Salzano FA, De Riu P, Biglioli F and De Riu G: Olfactory and gustatory function impairment in COVID-19 patients: Italian objective multicenter-study. Head Neck 42(7): 1560-1569, 2020. PMID: 32437022. DOI: 10.1002/hed.26269

26 Reden J, Mueller A, Mueller C, Konstantinidis I, Frasnelli J, Landis BN and Hummel T: Recovery of olfactory function following closed head injury or infections of the upper respiratory tract. Arch Otolaryngol Head Neck Surg 132(3): 265 269, 2006. PMID: 16549746. DOI: 10.1001/archotol.132.3.265

27 Lechien JR, Chiesa-Estomba CM, Beckers E, Mustin V, Ducarme M, Journe F, Marchant A, Jouffe L, Barillari MR, Cammaroto G, Circiu MP, Hans S and Saussez S: Prevalence and 6-month recovery of olfactory dysfunction: a multicentre study of 1363 COVID-19 patients. J Intern Med 290(2): 451461, 2021. PMID: 33403772. DOI: 10.1111/joim.13209

28 Konstantinidis I, Tsakiropoulou E, Hähner A, de With K, Poulas $\mathrm{K}$ and Hummel T: Olfactory dysfunction after coronavirus disease 2019 (COVID-19) vaccination. Int Forum Allergy Rhinol 11(9): 1399-1401, 2021. PMID: 34047498. DOI: 10.1002/alr. 22809

29 Hopkins C, Lechien JR and Saussez S: More that ACE2? NRP1 may play a central role in the underlying pathophysiological mechanism of olfactory dysfunction in COVID-19 and its association with enhanced survival. Med Hypotheses 146: 110406, 2021. PMID: 33246692. DOI: 10.1016/j.mehy. 2020.110406

30 Lechien JR, Michel J, Radulesco T, Chiesa-Estomba CM, Vaira LA, De Riu G, Sowerby L, Hopkins C and Saussez S: Clinical and radiological evaluations of COVID-19 patients with anosmia: preliminary report. Laryngoscope 130(11): 2526-2531, 2020. PMID: 32678494. DOI: 10.1002/lary.28993

31 Butowt $\mathrm{R}$ and von Bartheld CS: Anosmia in COVID-19: Underlying mechanisms and assessment of an olfactory route to brain infection. Neuroscientist 27(6): 582-603, 2021. PMID: 32914699. DOI: $10.1177 / 1073858420956905$

32 Brann DH, Tsukahara T, Weinreb C, Lipovsek M, Van den Berge K, Gong B, Chance R, Macaulay IC, Chou HJ, Fletcher RB, Das D, Street K, de Bezieux HR, Choi YG, Risso D, Dudoit S, Purdom E, Mill J, Hachem RA, Matsunami H, Logan DW, Goldstein BJ, Grubb MS, Ngai J and Datta SR: Non-neuronal expression of SARS-CoV-2 entry genes in the olfactory system suggests mechanisms underlying COVID-19-associated anosmia. Sci Adv 6(31): eabc5801, 2020. PMID: 32937591. DOI: 10.1126/sciadv.abc5801

33 Cheng MY, Hsih WH, Ho MW, Lai YC, Liao WC, Chen CY, Chen TC, Lee YL, Liu PY, Kao CC, Chou CH, Lin PC, Chi CY, Leong LY, Tai CJ and Lu MC: Younger adults with mild-tomoderate COVID-19 exhibited more prevalent olfactory dysfunction in Taiwan. J Microbiol Immunol Infect 54(5): 794800, 2021. PMID: 33610511. DOI: 10.1016/j.jmii.2021.01.006

34 Soler ZM, Patel ZM, Turner JH and Holbrook EH: A primer on viral-associated olfactory loss in the era of COVID-19. Int Forum Allergy Rhinol 10(7): 814-820, 2020. PMID: 32271490. DOI: $10.1002 /$ alr.22578

35 Doty RL and Kamath V: The influences of age on olfaction: a review. Front Psychol 5: 20, 2014. PMID: 24570664. DOI: 10.3389/fpsyg.2014.00020

36 Aziz M, Perisetti A, Lee-Smith WM, Gajendran M, Bansal P and Goyal H: Taste changes (dysgeusia) in COVID-19: a systematic review and meta-analysis. Gastroenterology 159(3): 1132-1133, 2020. PMID: 32387496. DOI: 10.1053/j.gastro.2020.05.003

37 Delinasios GJ, Fragkou PC, Gkirmpa AM, Tsangaris G, Hoffman $\mathrm{RM}$ and Anagnostopoulos AK: The experience of Greece as a model to contain COVID-19 infection spread. In Vivo 35(2): 1285-1294, 2021. PMID: 33622932. DOI: 10.21873/invivo. 12380

Received December 6, 2021

Revised December 20, 2021

Accepted December 22, 2021 